\title{
Antibacterial and Solubility Analysis of Experimental Phytotherapeutic Paste for Endodontic Treatment of Primary Teeth
}

Aldelany Ramalho Freire ${ }^{1}$, Deborah Ellen Wanderley Gomes Freire ${ }^{\circledR}$, Simone Alves de Sousa ${ }^{2}(\mathbb{0}$, Eliane Medeiros Serpa ${ }^{2}$, Leopoldina de Fátima Dantas de Almeida ${ }^{\circledR}$, Y Yri Wanderley Cavalcanti²®

'Graduate Program in Dentistry, School of Dentistry, Federal University of Paraíba, João Pessoa, PB, Brazil.

${ }^{2}$ Department of Clinical and Social Dentistry, School of Dentistry, Federal University of Paraíba, João Pessoa, PB, Brazil.

Correspondence: Prof. Yuri Wanderley Cavalcanti, Department of Clinical and Social Dentistry, Center for Health Sciences, Federal University of Paraíba, João Pessoa, PB, Brazil. E-mail: yuri@,ccs.ufpb.br

Academic Editor: Catarina Ribeiro Barros de Alencar

Received: 05 February 2020 / Review: 17 May 2020 / Accepted: 21 July 2020

How to cite this article: Freire AR, Freire DEWG, Sousa SA, Serpa EM, Almeida LFD, Cavalcanti YW. Antibacterial and solubility analysis of experimental phytotherapeutic paste for endodontic treatment of primary teeth. Pesqui Bras Odontopediatria Clín Integr. 202 1; 21 :e0007. https://doi.org/10.1590/pboci.2021.005

\begin{abstract}
Objective: To evaluate the antibacterial effect and the solubility of experimental root canal filling pastes containing the phytoconstituents terpineol and cinnamaldehyde. Material and Methods: Minimum Inhibitory Concentration (MIC) of each phytoconstituent was determined against Enterococcus faecalis. Five groups of antibiotic pastes based on zinc oxide were obtained by mixing: only terpineol, only cinnamaldehyde, terpineol and cinnamaldehyde combined, chlorhexidine (antibiotic control), and CTZ paste (control paste). Antibacterial activity was analyzed through direct contact test within 24 and 72 hours. Solubility was evaluated by spectrophotometry within 48 and 144 hours. Antibacterial activity data were analyzed descriptively, and solubility data was analyzed using ANOVA and Tukey tests $(\mathrm{p}<0.05)$. Results: The MIC obtained for terpineol and cinnamaldehyde were, respectively, $2000 \mu \mathrm{g} / \mathrm{mL}$ and $500 \mu \mathrm{g} / \mathrm{mL}$. After 24 h, only the terpineol paste did not inhibit E. faecalis growth. After $72 \mathrm{~h}$, all groups inhibited E. faecalis growth. After $48 \mathrm{~h}$, the highest solubility was verified in the terpineol paste $(\mathrm{p}<0.05)$, and no differences were detected among other groups $(\mathrm{p}>0.05)$. After and $144 \mathrm{~h}$, highest solubility was observed in the terpineol paste $(\mathrm{p}<0.05)$, followed by the CTZ paste $(\mathrm{p}<0.05)$. No differences were detected for cinnamaldehyde, terpineol+cinnamaldehyde and chlorhexidine pastes $(\mathrm{p}>0.05)$. Conclusion: Pastes containing cinnamaldehyde or terpineol+cinnamaldehyde showed antibacterial activity against E. faecalis similar to CTZ paste, with lower solubility.
\end{abstract}

Keywords: Root Canal Filling Materials; Tooth, Deciduous; Plant Extracts; Enterococcus faecalis. 


\section{Introduction}

Endodontic treatment of primary teeth presents particularities related to the complex anatomy and topography of its root canal system, showing sharp curvatures and several accessory channels [1]. Such characteristics make instrumentation hard and require the use of strategies to reduce or eliminate the remaining microorganisms. Therefore, antimicrobial sealing pastes' efficacy is an important aspect of posttreatment success [2,3].

In addition to the necessary antibacterial activity, several other properties are desirable to endodontic pastes, such as biocompatibility, radiopacity, no tooth discoloration or aggression to the successor permanent tooth germ, degradation similar to the physiological resorption process of the deciduous tooth, having low solubility in water, among others [4].

Among the root canal filling pastes indicated in literature, CTZ (chloramphenicol, tetracycline, zinc oxide and eugenol) presents satisfactory clinical results, as well as a simple and easy-to-perform technique $[3,5,6]$. However, this material is still not widely used, due to factors such as the fear of professionals regarding biocompatibility of the paste (a few numbers of studies analysed this propriety) [7] and the lack of studies that verified long-term clinical success of this therapy [3].

These challenges are necessary to search for new therapeutic products with antimicrobial activity capable of representing innovative and safe endodontic treatment alternatives for primary teeth. Under this perspective, it is possible to consider phytoconstituents' use because they present relevant biological properties against many microorganisms involved in endodontic infections [8-10].

Terpineol and cinnamaldehyde are phytoconstituents that show an important antimicrobial action $[11,12]$. Terpineol (terpinen-4-ol) is the main constituent of the essential oil TTO (tea tree oil) distilled from Melaleuca alternifolia [11]. Cinnamaldehyde (trans-cinnamaldehyde) is obtained from Cinnamomum zeylandicum, present in the cinnamon bark extract [13]. The use of terpineol and cinnamaldehyde in constitution of root canal filling pastes was not studied before, although these substances have therapeutic potential and vast parameters to be explored and tested.

Thus, this study aimed to evaluate the antibacterial effect and the solubility of experimental root canal filling pastes containing the phytoconstituents terpineol and cinnamaldehyde and compare them with the CTZ paste, frequently used in endodontic treatment of primary teeth.

\section{Material and Methods}

Microorganisms Used

Considering the major role of Enterococcus faecalis in endodontic infections, this study used the reference strain Enterococcus faecalis (ATCC 29212), obtained from the FIOCRUZ's collection of reference microorganisms. The strain was maintained in Brain Heart Infusion (BHI) culture medium enriched with 5\% defibrinated blood (blood agar). Standardized solutions of microorganisms were used at a concentration of $1 \times 108 \mathrm{CFU} / \mathrm{mL}$ determined in a spectrophotometer, at an absorbance of 0.1 , under $600 \mathrm{~nm}$ wavelength. The concentration of microorganisms established for the Minimum Inhibitory Concentration (MIC) assays was $1 \times 105 \mathrm{CFU} / \mathrm{mL}$, which was obtained by the $1000 \times$ dilution of the previously standardized inoculum.

Determination of Minimum Inhibitory Concentration (MIC) of Phytoconstituents

The MIC (lower concentration of substances capable of inhibiting the visible growth of the evaluated microorganisms) was determined according to the M7-A9 standardization of the Clinical Laboratory and 
Standards Institute (CLSI) [14], using the broth microdilution technique, developed in three independent experiments. Wells from a 96-well culture plate were filled with $100 \mu \mathrm{L}$ of the RPMI 1640 culture medium. Then, $100 \mu \mathrm{L}$ of phytochemical working solutions with concentration $8 \mathrm{mg} / \mathrm{mL}(8000 \mu \mathrm{g} / \mathrm{mL})$ were inserted into the first row wells of the microdilution plate. Subsequently, the serial dilution of the compounds was performed by transferring $100 \mu \mathrm{l}$ of the most concentrated well to the least concentrated, so the substances passed through serial dilutions of 1:2 (v/v). $100 \mu \mathrm{l}$ of Enterococcus faecalis bacterial inoculum (ATCC 29212) at $1 \times 105 \mathrm{CFU} / \mathrm{mL}$ was inserted into all wells. The samples were incubated at $37^{\circ} \mathrm{C}$ for 24 hours in microaerophilic. Viability control of microorganisms and sterility control of culture mediums were performed to guarantee accuracy of the method. The results were analyzed visually, considering the inhibition of microbial growth at the bottom of the wells.

Constitution of Antibiotic Pastes

The phytoconstituents terpineol (ref. 432628, SigmaAldrich, St. Louis, MO, USA) and cinnamaldehyde (ref. W228613, SigmaAldrich, St. Louis, MO, USA) were obtained is their pure form. Technical report of the substances, molecular weight, purity, density and other characteristics can be assessed in http//:www.sigmaaldrich.com/brazil. The phytoconstituents and controls $(0.1 \mathrm{~mL})$ were mixed by spatulation to $1 \mathrm{~g}$ zinc oxide powder p.a. (Biodinâmica Química e Farmacêutica LTDA, Ibiporã, PR, Brazil) until saturated, in order to obtain a paste-like consistency compatible with the material used as an intracanal medication of deciduous teeth. Four types of experimental root canal filling pastes were obtained: terpineol+ zinc oxide, cinnamaldehyde + zinc oxide, terpineol + cinnamaldehyde + zinc oxide, chlorhexidine + zinc oxide CTZ paste $(500 \mathrm{mg}$ of chloramphenicol, $500 \mathrm{mg}$ of tetracycline and $1000 \mathrm{mg}$ of zinc oxide, micronized using gral and pistil, and saturated in 1 drop of eugenol) was used as the standard for comparison.

\section{Evaluation of the Antibacterial Activity of Pastes}

The antibacterial effect of the pastes was evaluated by the direct contact test [15]. Test specimens (n=5/group) [16,17] were immersed in $2 \mathrm{ml}$ of culture medium containing E. faecalis bacterial inoculum (ATCC 29212) at $1 \times 108 \mathrm{CFU} / \mathrm{ml}$ concentration. After 24 and 72 hours, samples $(10 \mu \mathrm{L})$ of the culture medium inoculated by microorganisms were seeded using the Muller Hinton agar plates to verify the microorganisms' viability. The plates were incubated at $37^{\circ} \mathrm{C}$ for $24 \mathrm{~h}$, and after that period, the number of viable microorganisms was quantified.

\section{Evaluation of the Solubility of Pastes}

Test specimens from the test groups $(n=5)$ were packed in plastic matrices, obtained from $10 \mu \mathrm{L}$ sterile bacteriological loops. The specimens were inserted into wells of a 24-well culture dish, and in each of them was pipetted $1 \mathrm{ml}$ of distilled water. The plate was kept in an oven at $37^{\circ} \mathrm{C}$. The solubility of pastes was visually identified by the observation of residues in the containers and by the turbidity of the distilled water, verified in a spectrophotometer, at the wavelength of $600 \mathrm{~nm}$ [18-20].

\section{Data Analysis}

Data were tabulated and statistically analyzed in the Statistical Package for Social Sciences program (SPSS, v. 21, IBM, Chicago, IL, USA). The data obtained from the CIM and Direct Contact tests were analyzed 
descriptively, using means and standard deviation. The absorbance data passes obtained for the solubility test were evaluated by Analysis of Variance (ANOVA) by two factors (group and time), with Tukey post-hoc test, considering $\mathrm{p}<0.05$ and statistical power of $80 \%$. Kolmogorov-Smirnov test was used to confirm a normal distribution ( $p>0.05)$. The null hypothesis was that experimental pastes containing phytoconstituents do not differ from CTZ paste (control) regarding to antibacterial activity and solubility..

\section{Results}

The MICs obtained against Enterococcus faecalis for terpineol and cinnamaldehyde are shown in Table 1. Both results coincided with the CBM (Minimum Bactericidal Concentration) of each phytoconstituent.

Table 1. Minimum Inhibitory Concentration (MIC) and Minimum Bactericidal Concentration (MBC) obtained for Terpineol, Cinnamaldehyde and Chlorhexidine.

\begin{tabular}{cccc}
\hline Parameters & Terpineol & $\begin{array}{c}\text { Substances } \\
\text { Cinnamaldehyde }\end{array}$ & Chlorhexidine \\
\hline MIC & $2000.0 \mu \mathrm{g} / \mathrm{mL}$ & $500.0 \mu \mathrm{g} / \mathrm{mL}$ & $7.8125 \mu \mathrm{g} / \mathrm{mL}$ \\
MBC & $2000.0 \mu \mathrm{g} / \mathrm{mL}$ & $500.0 \mu \mathrm{g} / \mathrm{mL}$ & $7.8125 \mu \mathrm{g} / \mathrm{mL}$ \\
\hline
\end{tabular}

In the analysis of the antibacterial activity of antibiotic pastes against $E$. faecalis, only the terpineol paste could not inhibit the growth of the microorganism after $24 \mathrm{~h}$. After 72 hours, all analyzed pastes showed areas of inhibition, free of viable microorganisms. The results of the direct contact test are given in Table 2.

Table 2. Viability of the suspension of Enterococcus faecalis after direct contact test, according to the groups studied.

\begin{tabular}{cccccc}
\hline Time & \multicolumn{4}{c}{ Groups } \\
& GCTZ & GT & GC & GTC & GCHX \\
\hline $24 \mathrm{~h}$ & 0 & +++ & 0 & 0 & 0 \\
$72 \mathrm{~h}$ & 0 & 0 & 0 & 0 & 0 \\
\hline
\end{tabular}

Statistical analysis revealed that, within $48 \mathrm{~h}$, only the terpineol paste differed from the others, and no statistically significant differences were observed among CTZ paste, cinnamaldehyde paste, terpineol+cinnamaldehyde paste and chlorhexidine paste (Table 3). After and 144 h, highest solubility was observed in the terpineol paste $(\mathrm{p}<0.05)$, followed by the CTZ paste $(\mathrm{p}<0.05)$. No differences were detected for cinnamaldehyde, terpineol+cinnamaldehyde and chlorhexidine pastes $(\mathrm{p}>0.05)$ (Table 3$)$.

Table 3. Means and standard deviations of the absorbance at $600 \mathrm{~nm}$ used to assess the different pastes' solubility after 48 and 144 hours.

\begin{tabular}{cccccc} 
& & \multicolumn{4}{c}{ Groups } \\
Time & GCTZ & GT & GC & GTC & GCHX \\
\hline $48 \mathrm{~h}$ & $0.1346 \pm 0.0958$ & $2.0 \pm 0.0^{*}$ & $0.2334 \pm 0.0994$ & $0.1348 \pm 0.0070$ & $0.13625 \pm 0.2125$ \\
$144 \mathrm{~h}$ & $0.4360 \pm 0.2087^{*}$ & $2.0 \pm 0.0^{*}$ & $0.1352 \pm 0.1070$ & $0.0562 \pm 0.1450$ & $0.1823 \pm 0.0786$ \\
\hline
\end{tabular}

*Indicates a statistically significant difference in ANOVA test $(\mathrm{p}<0.05)$ regarding the other groups.

As shown in Figure 1, the solubility test showed a clear difference in the coloration of the solutions between the studied groups. The presence of a yellowish tone in the solution containing the CTZ paste was observed. It was possible to verify the total solubilization of the terpineol paste. 


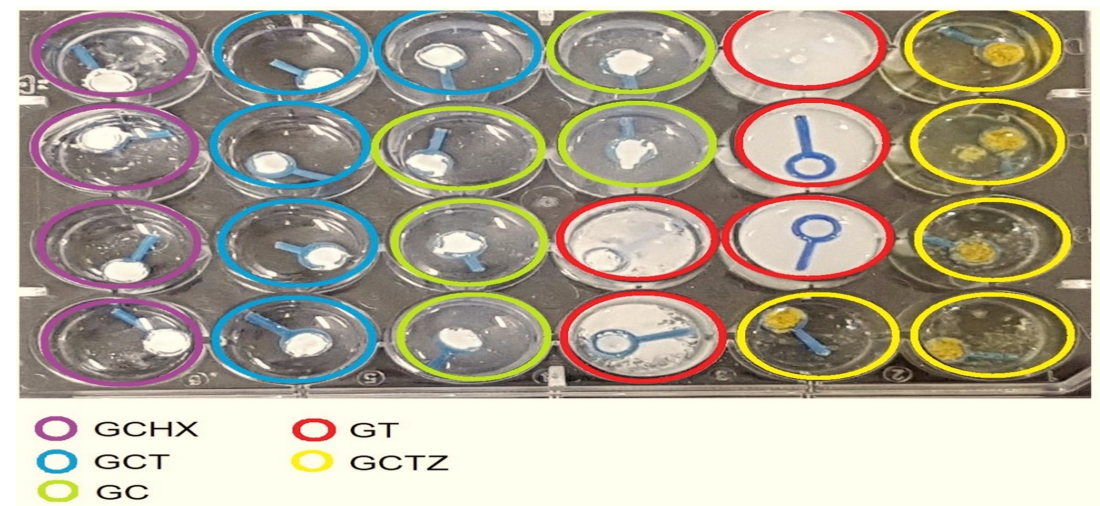

Figure 1. Solubility test of pastes after $48 \mathrm{~h}$. There are qualitative differences in the coloration of the solutions, especially in the GT and GCTZ groups.

\section{Discussion}

This study demonstrated that the paste composed by phytoconstituents terpineol and cinnamaldehyde showed antibacterial performance similar to the CTZ paste. E. faecalis was chosen as the reference microorganism because it is frequently found in endodontic infections of deciduous teeth and presents mechanisms of virulence and resistance to antimicrobials [21]. Regarding solubility, the paste consisted of combined phytoconstituents showed better results than CTZ paste after a longer observation time, showing a lower solubility. These results suggest that further investigations are necessary to assess the efficacy and effectiveness of phytoconstituent-based endodontic pastes.

Terpineol and cinnamaldehyde had their efficacy proven against different human pathogens [11]. However, literature is scarce regarding studies that evaluated antimicrobial activity of these isolated phytoconstituents against E. faecalis. Some authors [8,9,22-25] found a potent antibacterial effect of essential oils containing such phytoconstituents in their composition. However, since essential oils are complex mixtures of several compounds with different properties, the antimicrobial efficacy found in these investigations can not be attributed specifically to terpineol or cinnamaldehyde.

The results obtained in this research confirm the antimicrobial activity of terpineol and cinnamaldehyde against E. faecalis. The MIC values obtained coincided with the Minimum Bactericidal Concentration (MBC), indicating that, at those concentrations, the phytoconstituents can inhibit the growth of the E. faecalis and also have a bactericidal action, leading to its destruction. This study corroborates the MIC and $\mathrm{MBC}$ values found for terpineol and cinnamaldehyde against E. faecalis and other gram-positive bacterias [26-28].

The experimental root canal filling paste composed by combined phytoconstituents showed a better antibacterial effect than the one consisted of only terpineol. Previous studies have shown a synergism between terpineol and cinnamaldehyde when interacting with other essential oil components [27,29]. However, the paste composed of isolated cinnamaldehyde presented similar results that consisted of a combination of terpineol and cinnamaldehyde. Therefore, further studies are necessary to understand the interaction between these phytoconstituents better, requiring longer periods of observation to verify if these effects remain constant over time.

Regarding solubility test, the paste composed of terpineol alone showed results that were not very encouraging in this respect, undergoing it to total solubilization within $48 \mathrm{~h}$. In addition, CTZ also presented higher solubility within $144 \mathrm{~h}$. CTZ elicited a yellowish coloration in the solution, that became even more 
intense over time. This is probably due to the presence of tetracycline, which gives such coloration to the CTZ paste. The liberation of pigments by CTZ in aqueous medium may strengthen the theory described in the literature that the material represents a risk factor for color change in the successor permanent teeth, causing yellowish or brownish spots, due to the impregnation of tetracycline with dental tissues [30]. However, there is no evidence about this effect, and the occurrence of defects in the enamel of permanent teeth seems to be more related to the inflammatory process in the periapical region of deciduous tooth, due to the carious process $[31,32]$.

The analysis of the results of this study showed that the paste composed by the combination of the two phytoconstituents presented good results in relation to the solubility and antibacterial activity against $E$. faecalis. Thus, its use in endodontic treatment of primary teeth would represent a viable alternative in a superficial analysis. However, this study has some limitations, such as the use of only one reference microorganism in planktonic form and the absence of simulation of conditions similar to those found in the oral environment. This is a preliminary study, and the application of this paste in the clinical practice of pediatric dentistry requires another in vitro and in vivo studies that considered several other variables, such as biocompatibility, stability, and security.

\section{Conclusion}

Experimental root canal filling pastes containing cinnamaldehyde or terpineol+cinnamaldehyde showed antibacterial activity against E. faecalis similar to CTZ paste, and lower solubility. Further studies must be carried out to analyze the viability and security of root canal filling pastes with terpineol and cinnamaldehyde.

\section{Authors' Contributions}

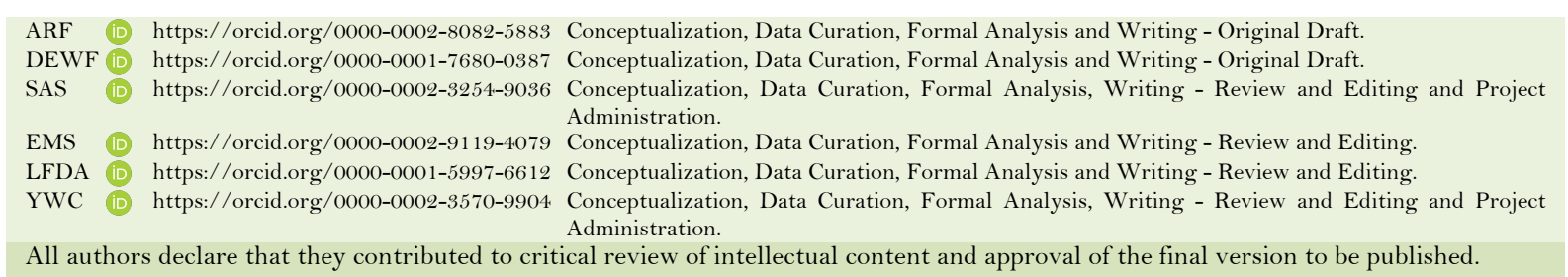

\section{Financial Support}

None.

\section{Conflict of Interest}

The authors declare no conflicts of interest.

\section{Data Availability}

The data used to support the findings of this study can be made available upon request to the corresponding author.

\section{References}

[1] Ahmed HMA. Anatomical challenges, electronic working length determination and current developments in root canal preparation of primary molar teeth. Int Endod J. 2013; 46(11):1011-22. https://doi.org/10.1111/iej.12134

[2] Barja-Fidalgo F, Moutinho-Ribeiro M, Oliveira MAA, de Oliveira BH. A systematic review of root canal filling materials for deciduous teeth: is there an alternative for zinc oxide-eugenol? ISRN Dent 2011; 2011:367318. https://doi.org/10.5402/2011/367318 
[3] Luengo-Fereira J, Ayala-Jiménez S, Carlos-Medrano LE, Toscano-García I, Anaya-Álvarez M. Clinical and radiographic evaluation of formocresol and chloramphenicol, tetracycline and zinc oxide-eugenol antibiotic paste in primary teeth pulpotomies: 24 month follow up. J Clin Pediatr Dent 2019; 43(1):16-21. https://doi.org/10.17796/1053-4625-43.1.4

[4] Segato RAB, Pucinelli CM, Ferreira DCA, Daldegan ADR, Silva RS, Nelson-Filho P, et al. Physicochemical properties of root canal filling materials for primary teeth. Braz Dent J 2016; 27(2):196-201. https://doi.org/10.1590/0103-6440201600206

[5] Moura LFAD, Lima MDM, Lima CCB, Machado JIAG, Moura MS, Carvalho PV. Endodontic treatment of primary molars with antibiotic paste: a report of 38 cases. J Clin Pediatr Dent 2016; 40(3):175-7. https://doi.org/10.17796/1053-4628-40.3.175

[6] Lokade A, Thakur S, Singhal P, Chauhan D, Jayam C. Comparative evaluation of clinical and radiographic success of three different lesion sterilization and tissue repair techniques as treatment options in primary molars requiring pulpectomy: an in vivo study. J Indian Soc Pedod Prev Dent 2019; 37(2):185-91.

https://doi.org/10.4103/JISPPD.JISPPD_6_19

[7] Lima CCB, Conde Júnior AM, Rizzo MS, Moura RD, Moura MS, Lima MDM, et al. Biocompatibility of root filling pastes used in primary teeth. Int Endod J 2015; 48(5):405-16. https://doi.org/10.1111/iej.12328

[8] Gupta A, Duhan J, Tewari S, Sangwan P, Yadav A, Singh G, et al. Comparative evaluation of antimicrobial efficacy of Syzygium aromaticum, Ocimum sanctum and Cinnamomum zeylanicum plant extracts against Enterococcus faecalis: a preliminary study. Int Endod J. 2013; 46(8):775-83. https://doi.org/10.1111/iej.12058

[9] Abbaszadegan A, Gholami A, Ghahramani Y, Ghareghan R, Ghareghan M, Kazemi A, et al. Antimicrobial and cytotoxic activity of cuminum cyminum as an intracanal medicament compared to chlorhexidine gel. Iran Endod J 2016; 11 (1):44-50. https://doi.org/10.7508/iej.2016.01.009

[10] Barbieri R, Coppo E, Marchese A, Daglia M, Sobarzo-Sánchez E, Nabavi SF, et al. Phytoconstituents for human disease: An update on plant-derived compoundsantibacterial activity. Microbiol Res 2017; 196:44-68. https://doi.org/10.1016/j.micres.2016.12.003

[11] Sharifi-Rad J, Salehi B, Varoni EM, Sharopov F, Yousaf Z, Ayatollahi AS, et al. Plants of the melaleuca genus as antimicrobial agents: from farm to pharmacy. Phytother Res 2017; 31(10):1475-94. https://doi.org/10.1002/ptr.5880

[12] Bhinge SD, Bhutkar MA, Randive DS, Wadkar GH, Todkar SS, Kakade PM, et al. Formulation development and evaluation of antimicrobial polyherbal gel. Ann Pharm Fr 2017; 75(5):349-58. https://doi.org/10.1016/j.pharma.2017.04.006

[13] Upadhyay A, Venkitanarayanan K. In vivo efficacy of trans-cinnamaldehyde, carvacrol, and thymol in attenuating Listeria monocytogenes infection in a Galleria mellonella model. J Nat Med 2016; 70(3):667-72. https://doi.org/10.1007/s11418-016-0990-4

[14] CLSI. Methods for Dilution Antimicrobial Susceptibility Tests for Bacteria That Grow Aerobically; Approved Standard-Tenth Edition. CLSI document Mo7-A 10. Wayne, PA: Clinical and Laboratory Standards Institute; 2015.

[15] Huang Y, Li X, Mandal P, Wu Y, Liu L, Gui H, et al. The in vitro antimicrobial activities of four endodontic sealers. BMC Oral Health 2019; 19:118. https://doi.org/10.1186/s12903-019-0817-2

[16] Basir L, Khanehmasjedi M, Khosravi A, Ansarifar S. Investigating the antimicrobial activity of different root canal filling pastes in deciduous teeth. Clin Cosmet Investig Dent 2019; 11:321-6. https://doi.org/10.2147/CCIDE.S2 14568

[17] Cavalcanti YW, Almeida LFD, Padilha WWN. Antimicrobial activity and pH evaluation of calcium hydroxide associated with natural products. Braz Dent Sci 2010; 13(8):49-54. https://doi.org/10.14295/bds.2010.v13i3/4.686

[18] Manno BR, Abukhalaf IK, Manno JE. A simple spectrophotometric assay for the measurement of soluble silica in water. J Anal Toxicol 1997; 21(6):503-5. https://10.1093/jat/2 1.6.503

[19] Bertolini MM, Portela MB, Curvelo JAR, Soares RMA, Lourenço EJV, Telles DM. Resins-based denture soft lining materials modified by chlorhexidine salt incorporation: an in vitro analysis of antifungal activity, drug release and hardness. Dent Mater 2014; 30(8):793-8. https://doi.org/10.1016/j.dental.2014.05.004

[20] Tyagi S, Thomas AM, Sinnappah-Kang ND. A comparative evaluation of resin- and varnish-based surface protective agents on glass ionomer cement - a spectrophotometric analysis. Biomater Investig Dent 2020; 7(1):25-30. https://doi.org/10.1080/26415275.2020.1711760

[21] Cancio V, Ferreira DC, Cavalcante FS, Rosado AS, Teixeira LM, Oliveira QB, et al. Can the Enterococcus faecalis identified in the root canals of primary teeth be a cause of failure of endodontic treatment?. Acta Odontol Scand 2017; 75(6):423-8. https://doi.org/10.1080/00016357.2017.1328742

[22] Martos J, Ferrer Luque CMF, González-Rodríguez MP, Arias-Moliz MT, Baca P. Antimicrobial activity of essential oils and chloroform alone and combinated with cetrimide against Enterococcus faecalis biofilm. Eur J Microbiol Immunol 2013; 3(1):44-8. https://doi.org/10.1556/EuJMI.3.2013.1.6

[23] Benbelaïd F, Khadir A, Abdoune MA, Bendahou M, Muselli A, Costa J. Antimicrobial activity of some essential oils against oral multidrug-resistant Enterococcus faecalis in both planktonic and biofilm state. Asian Pac J Trop Biomed 2014; 4(6):463-72. https://doi.org/10.12980/APJTB.4.2014C1203 
[24] Smolarek PC, Esmerino LA, Chibinski AC, Bortoluzzi MC, Santos EB, Kozlowski Junior VA. In vitro antimicrobial evaluation of toothpastes with natural compounds. Eur J Dent 2015; 9(4):580-6. https://doi.org/10.4103/1305-7456.172632

[25] Borzini L, Condò R, Dominicis P, Casaglia A, Cerroni L. Root canal irrigation: chemical agents and plant extracts against Enterococcus faecalis. Open Dent J 2016; 10:692-703. https://doi.org/ 10.2174/1874210601610010692

[26] Park S, Lim YK, Freire MO, Cho E, Jin D, Kook J. Antimicrobial effect of linalool and $\alpha$-terpineol against periodontopathic and cariogenic bacteria. Anaerobe 2012; 18(3):369-72. https://doi.org/ 10.1016/j.anaerobe.2012.04.001

[27] Zengin H, Baysal AH. Antibacterial and antioxidant activity of essential oil terpenes against pathogenic and spoilageforming bacteria and cell structure-activity relationships evaluated by SEM microscopy. Molecules 2014; 19(11):17773-98. https://doi.org/10.3390/molecules 191117773

[28] Ferro TAF, Araújo JMM, Pinto BLDS, Santos JS, Souza EB, Silva BLR, et al. Cinnamaldehyde inhibits Staphylococcus aureus virulence factors and protects against infection in a Galleria mellonella model. Front Microbiol 2016; 7:2052. https://doi.org/10.3389/fmicb.2016.02052

[29] Liu Q, Niu H, Zhang W, Mu H, Sun C, Duan J. Synergy among thymol, eugenol, berberine, cinnamaldehyde and streptomycin against planktonic and biofilm-associated food-borne pathogens. Lett Appl Microbiol 2015; 60(5):42 130. https://doi.org/10.1111/lam.12401

[30] Boast A, Curtis N, Gwee A. QUESTION 1: Teething issues: can doxycycline be safely used in young children?. Arch Dis Child 2016; 101(8):772-4. https://doi.org/10.1136/archdischild-2016-310964

[31] Costa FS, Silveira ER, Pinto GS, Nascimento GG, Thomson WM, Demarco FF. Developmental defects of enamel and dental caries in the primary dentition: a systematic review and meta-analysis. J Dent 2017; 60:1-7. https://doi.org/10.1016/j.jdent.2017.03.006

[32] Vargas-Ferreira F, Salas MMS, Nascimento GG, Tarquinio SBC, Faggion Jr CM, Peres MA, et al. Association between developmental defects of enamel and dental caries: a systematic review and meta-analysis. J Dent 2015; 43(6):619-28.https://doi.org/10.1016/j.jdent.2015.03.011 